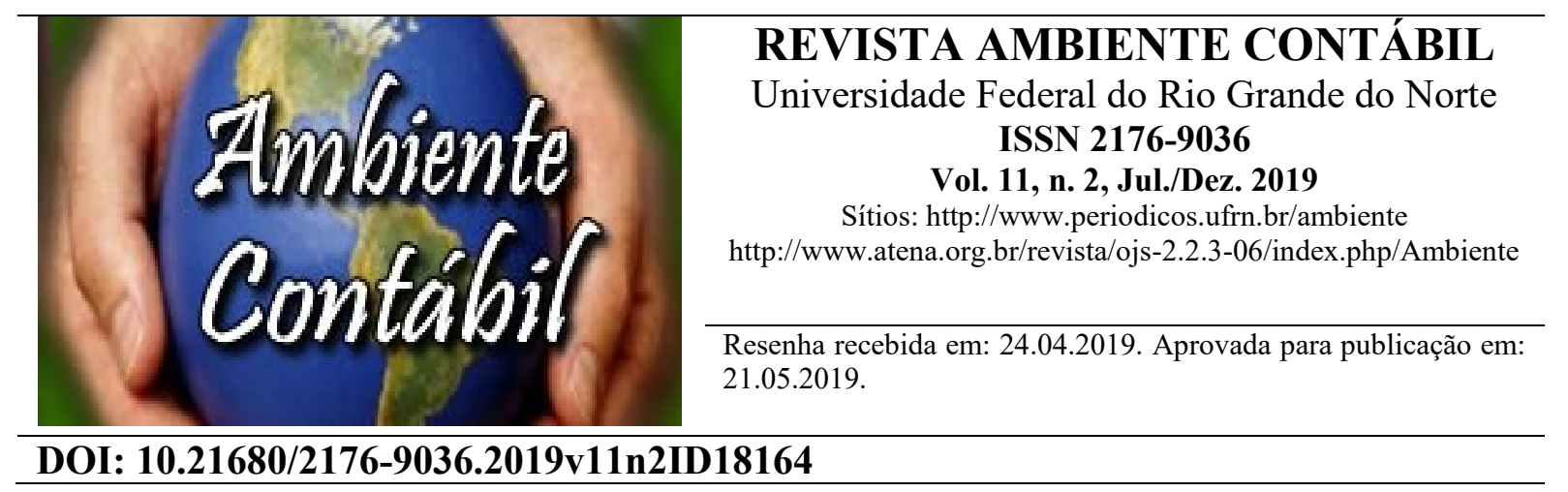

Resenha do Livro: Análise de custos e preços de venda: ênfase em aplicações e casos nacionais. Wernke, R. (2019). (2 ed.). São Paulo: Saraiva Educação, 234 páginas, ISBN: 978-85-5313184-6.

Book review: Analysis of costs and sales prices: emphasis on national applications and cases. Wernke, R. (2019). (2nd edition). São Paulo: Saraiva Educação, 234 pages, ISBN: 978-8553131-84-6.

Reseña del Libro: Análisis de costes y precios de venta: énfasis en aplicaciones y casos nacionales. Wernke, R. (2019). (2a ed). São Paulo: Saraiva Educação, 234 pages, ISBN: 97885-53131-84-6.

\title{
Marijane Felippe
}

\section{Autora}

Graduação em Administração/UNISUL. Especialização em Gestão Pública/IPEMIG. Chefa de Gabinete da Prefeitura Municipal de Morro da Fumaça/SC. Endereço: Rua Antônio Zanella, ${ }^{\circ}$ 83, Centro, Pedras Grandes (SC) - Brasil, CEP 88720-000 - Telefone: (48) 99183-3766 99904-3949

E-mail: marijanefelippepg@hotmail.com

\section{Resumo}

A resenha tem o objetivo de apresentar uma síntese do livro do Professor Rodney Wernke, da Universidade do Sul de Santa Catarina (UNISUL), lançado no início do ano de 2019, pela editora Saraiva Educação.

Palavras-chaves: Custos. Preços. Métodos de Custeio.

\begin{abstract}
The review has the objective of presenting a synthesis of Professor Rodney Wernke's book, both from the University of Southern Santa Catarina (UNISUL), published in early 2019, by Saraiva Educação.
\end{abstract}

Keywords: Costs. Prices. Costing Methods.

\section{Resumen}

La reseña tiene el objetivo de presentar una síntesis del libro del Profesor Rodney Wernke, de la Universidad del Sur de Santa Catarina (UNISUL), lanzado a principios del año de 2019, por la editorial Saraiva Educação. 
Palabras clave: Costes. Precios. Métodos de Costeo.

\section{Apresentação da origem da obra e dos autores:}

Este livro prioriza a utilização dos conceitos da gestão de custos e preços em contextos brasileiros. Por isso, além das definições e comentários sobre os benefícios e limitações das ferramentas gerenciais abordadas, traz também exemplos numéricos, exercícios de fixação e estudos de casos que mostram aplicações práticas em empresas do Brasil para facilitar a compreensão do leitor.

Com base na experiência como consultor de custos e gestão financeira em organizações de diversos segmentos e portes, além de atuar como professor universitário (em cursos de graduação e pós-graduação), o autor elaborou um livro que evidencia os passos necessários para utilizar os conceitos abrangidos no cotidiano de empresas nacionais.

\section{Análise de suas seções/capítulos:}

A obra é constituída de quatro partes, sendo que a primeira discorre sobre as definições dos principais termos desta área e as classificações de custos, que são necessários para compreender e aplicar o conteúdo dos capítulos seguintes.

A segunda parte abrange os principais métodos de custeio (Absorção, ABC, UEP, Direto/Variável e o TDABC, que foi acrescentado nesta segunda edição). Para cada uma dessas metodologias de custeamento são apresentados os conceitos pertinentes, as vantagens e desvantagens associadas, exemplos de cálculo, exercícios de fixação e aplicações práticas em empresas.

A terceira parte aborda os integrantes da Análise Custo-Volume-Lucro (CVL). No capítulo sobre Margem de Contribuição mostra como utilizar as informações oriundas para gerenciar os segmentos de mercado com os quais a empresa atua. O capítulo sobre Ponto de Equilíbrio destaca definições, fórmulas e exemplos numéricos das principais modalidades deste indicador. Por último, no capítulo sobre Margem de Segurança constam os conceitos e equações a respeito, além de um estudo de caso que retrata a aplicação detalhada da Análise CVL numa empresa varejista.

A quarta parte começa com capítulo que trata da determinação do preço de venda orientativo e abrange o cálculo do custo de compra e da taxa de marcação (ou mark-up). Na sequência vêm dois capítulos sobre aplicações da matemática financeira na gestão de compras e vendas. O capítulo seguinte mostra as três formas mais conhecidas de estabelecer o preço de venda a prazo, destacando as deficiências das duas mais comuns e enfatizando a metodologia 
mais consistente para essa finalidade. O penúltimo capítulo discute como os prazos do ciclo operacional (pagamento de compras, estocagem e recebimento de vendas) influenciam no resultado da venda e como mensurar esse efeito. O último capítulo, acrescentado na segunda edição, versa sobre a gestão de estoques e destaca como mensurar o custo financeiro da estocagem, o prazo médio de estoques, o nível de estoque excedente etc.

Convém salientar que, por ter finalidade didática, o livro conta com material de apoio no site da editora, o que envolve planilhas Excel com a resolução dos exercícios numéricos e arquivos Power Point para uso dos professores que utilizarem-no em suas aulas.

\section{Contribuição da obra para a área de estudo respectiva:}

O livro contribui para a compreensão dos conceitos e classificações de custos, métodos de custeio e ferramentas gerenciais utilizados por administradores que atuam na área de custos e preços de venda. Nesse sentido, o detalhamento dos exemplos numéricos auxilia o leitor a entender os procedimentos de cálculo de modo a permitir a aplicação no cotidiano empresarial. Além disso, os exercícios de fixação teóricos e práticos (bem como a resolução dos exercícios numéricos em planilhas eletrônicas) são facilitadores do aprendizado, pois ajudam a associar a teoria da literatura com a prática gerencial vivenciada em empresas brasileiras.

\section{Indicação do público de interesse da obra em questão:}

Este livro é indicado para profissionais que trabalham na gestão de custos e preços de venda e para alunos e professores de cursos de graduação e pós-graduação das áreas de Contabilidade, Administração e Engenharia de Produção que tratam desses temas.

\section{Indicação do sítio eletrônico para obter a obra ou mais informações:}

O livro está disponível no sítio eletrônico da editora: https://busca.saraiva.com.br/q/rodney-wernke

\section{Referências}

Wernke, R. (2019). Análise de custos e preços de venda: ênfase em aplicações e casos nacionais. (2nd ed.). São Paulo: Saraiva Educação. 